\title{
Ser-se Estrangeiro: Forjas (A)poéticas de Desterritorialização
}

\author{
Lucas Augusto da Silva*
}

Conta o escritor angolano Pepetela, na primeira página de seu livro $A$ geração da utopia (1992), que, em uma prova pública ocorrida em Lisboa na qual era arguido, foi-lhe apresentada uma questão à qual iniciou sua resposta com a palavra "portanto". O professor prontamente o corrigiu, dizendo-lhe que, pelas regras gramaticais vigentes da língua portuguesa, nunca seria possível principiar um raciocínio com tal palavra. Destacou ainda que a função gramatical de "portanto" residia na conclusão a uma ideia previamente estabelecida, além de afirmar que o examinando não sabia falar português.

Trinta anos (e alguns litros de rancor represados) depois, o escritor começa o romance retrocitado da seguinte forma: "Portanto, só os ciclos eram eternos". Segundo Charles Bernstein, Pepetela poderia ser classificado como um poeta contemporâneo - embora nunca tenha publicado um livro de poesia. A primeira lição do (a-)poeta estadunidense estabelece que "a poesia é a aversão à conformidade" (Bernstein, 1997, p. 102). Pode-se entender que a linguagem poética é uma forma de rejeição aos parâmetros formais, convencionais. De outro modo, se trata de desnudar o cânone e, portanto, revelar sua fragilidade ao abalar suas estruturas mais consolidadas.

Contudo, tão importante quanto a audácia de Pepetela é a reprimenda apresentada pelo professor. Na função de soldado em alto brado pelo idioma intocável, imaculável, estático, a correção demonstra alegoricamente como funciona a "política da linguagem" (BERnsteIn, 1997, p. 110), isto é, o conjunto de convenções que determinam o que é ou não aceitável dentro dos limites estabelecidos pelo cânone gramático-literário. A imposição de um comportamento linguístico oficial como componente estratégica de exclusão remonta a tempos ainda mais antigos.

O próprio processo colonizatório que recaiu sobre os povos ameríndios do Sul, a partir do fim do século XV, reconhece que a disseminação da religião católica, através da catequização jesuíta, em conjunto com a imposição dos idiomas estrangeiros (português e espanhol) como oficiais, dentro dos novos territórios co-

Poeta e doutorando em "Discursos: Cultura, História e Sociedade" pelo Centro de Estudos Sociais da Universidade de Coimbra (CES/UC) em Portugal. E-mail: augustodasilva.lucas@gmail.com / lucassilva@ces.uc.pt. 
lonizados, faziam parte da reorganização cultural no plano ideológico (RIBEIRo, 2006, p. 69).

Já no século XX, as mesmas estruturas (a religião e o idioma) serviram de base para uma espécie de neocolonialismo fragmentado em expressões de localismos globalizados (fenômenos locais que com sucesso são globalizados) e globalismos localizados (práticas transnacionais que modificam as condições locais) (SANTos, 1997, p. 16-17), sustentados pela organização econômica capitalista em uma trama que se pretende universal.

Com efeito, as noções de Boaventura de Sousa Santos (1997) prolongam os aspectos descritos como des- e re-territorialização de que tratam os franceses Gilles Deleuze e Félix Guattari ao analisar a obra literária de Franz Kafka. Os autores se preocupam em situar o escritor dentro de seu contexto histórico: trata-se do judeu que insistia em escrever em alemão, apesar de ter crescido em um território dominado pelo Império Austro-Húngaro onde tal idioma era "uma língua desterritorializada, própria a estranhos usos menores” (Deleuze e Guattari, 1977, p. 26).

A síntese que Kafka faz em seus textos, ao conjugar conteúdo e forma literários, identifica o que Deleuze e Guattari chamaram de literatura menor. Tal ideia se reflete em três quesitos inerentes: (i) a desterritorialização da língua, (ii) a ramificação do individual no imediato-político e (iii) o agenciamento coletivo da enunciação (Deleuze e Guattari, 1977, p. 28).

Para o debate aqui proposto, nos é bem-vindo focar na primeira característica. Segundo os pensadores franceses, a própria linguagem já é um processo de desterritorialização da boca. Isto é, uma vez que a boca tem como objetivo primitivo a alimentação, o ato de articular a fala já se trata de uma ressignificação de sua finalidade original (comer). Como apontam Deleuze e Guattari (1977, p. 30), "falar, e sobretudo escrever, é jejuar", ou seja, o exercício da linguagem é sempre uma renúncia (neste caso, ao alimento).

Os autores ainda evidenciam que, em Kafka, especialmente em suas novelas, a figura do animal (em seu processo de se tornar animal) funciona como emblema essencial do processo de desterritorialização. Esta "metamorfose", ou seja, o ato de transmutar-se de homem para animal, reflete uma tentativa de a personagem encontrar uma saída, traçar uma rota de fuga. Isto porque somente a passagem de um corpo para outro é que permite simultaneamente o deixar-de-ser-homem (desterritorializar-se de seu semblante) e tornar-se-animal (reterritorializar-se num outro), a ponto de estabelecer "meios de fuga nos quais o homem jamais teria pensado sozinho" (Deleuze e Guattari, 1977, p. 54).

Destarte, a primeira discussão que pretendo aqui encaminhar é a seguinte: no processo de colonização, quem é o estrangeiro desterritorializado? A questão atualizada para o contemporâneo seria: e no processo de globalização? É a escritora ucraniana-pernambucana Clarice Lispector que encaminha a reflexão pioneira neste ensaio. 


\section{Ofélia: a colonização disfarçada de ingenuidade}

Em "A legião estrangeira", conto cujo título também dá nome ao livro de 1964, a narradora traz à sua casa uma "coisa breve e amarela" (LISPECTOR, 2016, p. 198), um pinto. $\mathrm{O}$ enredo central gira em torno da relação estabelecida entre ela, a narradora, e Ofélia Maria dos Santos Aguiar, a arrogante menina de oito anos, filha do casal vizinho de condomínio. A subserviência da mulher que conta a estória diante da garota (adivinha, conselheira, cirúrgica nas intervenções sobre a organização da casa da outra) parece acabar quando finalmente o pinto chega. Até ali, trata-se de uma relação de poder que se sustenta na tensão entre a compaixão pelo mais fraco e o desejo de dominação, temperada por uma articulação adjacente que o elo mais frágil da relação sustenta: a impaciência pela exploração abafada pela confortável passividade. O pinto, no entanto, muda o rumo da prosa.

O pinto representa tudo o que de mais ameaçador há na posição do dominante: a plena e irrazoável liberdade de decidir sobre a vida de alguém/algo. Compadecida, a narradora, dona do pinto e, portanto, plena dona de sua salvação, confessa: "Sei que não lhe deveria ter dado a escolha, e então ela teria a desculpa de que fora obrigada a obedecer. Mas naquele momento não era por vingança que eu the dava o tormento da liberdade" (Lispector, 2016, p. 204).

Até então a narradora assumia o papel de estrangeira em seu território natal (desterritorializada, portanto). Depois da oferta da liberdade à criança, Ofélia pede licença para deixar a casa da narradora. Não decide sair, pede licença, isto é, já aceita que seu período de dominação acabou quando matara o pinto na cozinha. Sai da casa para, então, voltar a "ser a princesa hindu por quem no deserto sua tribo esperava” (Lispector, 2016, p. 205). Em síntese, Ofélia voltou a seu status de estrangeira quando a narradora deixou de sê-lo - em sua própria casa.

Assim como para Kafka, coincidentemente (ou não), Clarice adota uma imagem animalesca - o pinto - para representar simbolicamente ${ }^{1}$ a passagem de um estado de servidão para um estado de fuga re-territorializadora.

Ofélia, assim, assume metaforicamente a posição de colonizador que impõe discursivamente ao colonizado o sentimento de estrangeirismo mesmo dentro de sua terra natal. No conto, em dado momento, a menina de oito anos repreende a narradora por ter comprado legumes em demasia na feira e informa que não haveria espaço para todos eles na geladeira. Ofélia, que sequer residia naquela casa, que sequer teria ingerência sobre o que deveria ser comprado na feira naquela casa e em qual quantidade, sugere que a narradora havia cometido um erro. $\mathrm{Na}$ cena seguinte, a narradora compra, então, menos legumes do que da vez anterior. A garota olha e diz: "é pouco até a feira que vem" (Lispector, 2016, p. 200).

\footnotetext{
É certo, porém, que, para Deleuze e Guattari, as metamorfoses kafkanianas nada têm de metafórico. São, a bem da verdade, expressões de "uma fuga criadora, que nada quer dizer além dela mesma” (Deleuze e Guattari, 1977, p. 54).
} 
Clarice conta na próxima linha: "Os legumes acabaram pelo meio da semana" (LISPECTOR, 2016, p. 200).

Alfredo Bosi, eminente literato brasileiro, explica que a palavra colonização tem a mesma origem etimológica da palavra cultura: "derivam do mesmo verbo latino 'colo', cujo particípio passado é cultus e o particípio futuro é culturus" (BosI, 1992, p. 11).

O processo colonizatório abrange, portanto, a ideia de aculturamento, de assimilação coercitiva dos membros da comunidade colonizada à cultura do colonizador, o qual, como explica Bosi (1992, p. 13-17), já tem memória constituída (passado: cultus) e, pela colonização, persegue a reprodução de um estado de coexistência social (futuro: culturus). Ao tomar as rédeas da organização da feira da casa da narradora, Ofélia inculca (cultiva) sua própria maneira de agir a uma interlocutora que, presumindo estar errada, aceita seus conselhos.

O cumprimento das profecias de Ofélia dotou-a de uma especial submissão por parte da narradora de modo que a manipulação de sua ingenuidade a elevou a um espectro totêmico, tal qual acontece reciprocamente no processo de colonização. Como bem apontou Boaventura de Sousa Santos, "descobrir um ser humano implica reciprocidade. Quem descobre é descoberto” (1993, p. 6-7).

Mas nunca é descobrir. Melhor: é sempre revelar, ao melhor modo António Telmo de pensar este vocábulo. O filósofo português indica que a palavra revelação tanto se distanciou de sua procedência etimológica que hoje tem o significado contrário. Revelar seria, por sua origem, velar novamente, isto é, re-encobrir, re-ofuscar. Atualmente, porém, ao nos expressarmos sobre a revelação de um segredo ou de uma fotografia, nos referimos ao aparecimento, ao des-encobrimento de algo que até aquele momento estava escondido (Telmo, 1993). A conclusão do filósofo, todavia, demonstra porque este ensaio está no livro Arte poética: revelar é sempre a simultaneidade entre descobrir e encobrir com novos disfarces.

Na relação colonial, a reorganização cultural busca a supressão do passado do colonizado, a partir de uma ressignificação da identidade coletiva: um processo, portanto, de re-velação. A narradora de "A legião estrangeira" descomplica o conceito logo no início do conto: "Estou tentando falar daquela família que sumiu há anos sem deixar traços em mim, e de quem ficara apenas uma imagem esverdeada pela distância" (LISPECTOR, 2016, p. 197).

O ponto de convergência entre os processos de colonização e globalização são deflagrados por Clarice Lispector na relação entre a narradora do conto "A legião estrangeira" e Ofélia, a garota de oito anos: na medida em que o presente se relaciona mais com o futuro do que com o passado, o legado cultural também é atualizado. A imagem esverdeada - talvez porque o verde seja a cor da qual os olhos humanos mais distinguem tonalidades - aparece como um espectro que, embora exista, não deixa traços acessíveis pela memória. 
Estes estímulos centrífugos de aculturamento abrem espaço, a longo prazo, para uma espécie de xenofobia inversa, a repulsa criada discursivamente em um território contra os habitantes dele originários. Os discursos de ódio contra os indígenas no Brasil, contra os chicanos no Texas ou na Califórnia (e contra os peles vermelhas em todos os Estados Unidos) ou contra os palestinos em Jerusalém são emblemas contemporâneos desta tendência deletéria.

A inversão da xenofobia de que trato aqui é o processo cultural que, ao eleger um paradigma platônico de cultura superior, ajuda a alimentar um sentimento de aversão às expressões folclóricas locais. A ideia de barbárie, neste caso, resultaria da manutenção da organização cultural de dentro e o progresso civilizacional, ao contrário, se direcionaria à incorporação de práticas forasteiras.

O que Ofélia tentava impingir à narradora do conto de Clarice era uma narrativa de progresso cujo paradigma maior era o seu próprio discurso. Em outras palavras, a saída da barbárie rumo à civilização, para Ofélia, tinha por objetivo transformar a dona da casa, a narradora, numa criatura a imagem e semelhança da garota de oito anos. Tal qual a relação entre metrópole e colônia.

\section{A globalização enquanto amerdicanizamento}

Em "Discourse on the logic of language", Marlene Nourbese Philip escreve e declama em língua inglesa, sua língua-pai, uma vez que o idioma de seus ancestrais (sua língua-mãe) já não funciona em sua ação comunicativa. O poema, um balbucio de aliterações que (con)funde voluntariamente, por exemplo, "mãe" e "múmia", enuncia uma, e depois duas vezes, que "o inglês é minha língua-pai / uma línguapai é um idioma estrangeiro / (...) um idioma estrangeiro / não é uma língua-mãe" (PHILIP, 1989, p. 12, tradução nossa). A orfandade contraedipiana que a escritora de Trinidad e Tobago apresenta é reflexo de um processo predatório que impõe o esquecimento através da substituição por uma nova memória.

Se nos processos modernos de colonização o idioma (junto da religião) se tornou instrumento de expansão da cultura colonizadora, no intuito de apagar as origens culturais locais (torná-las apenas uma imagem esverdeada pela distância), a conjuntura contemporânea da globalização - por acontecer em um contexto universal de progresso político rumo à democratização e ao republicanismo - busca homogeneizar e universalizar a língua, relegando os idiomas diferentes a uma categoria "ex-cêntrica". Como sugere Boaventura de Sousa Santos, a propagação da língua inglesa "enquanto língua global implicou a localização de outras línguas potencialmente globais” (SANTOS, 1997, p. 15). No jogo de forças simbólicas, estruturado pelo poder econômico das grandes nações, somente um idioma pode ser oficial (portanto, global), enquanto os demais não precisam necessariamente desaparecer, mas não extravasam as fronteiras de seu território original.

A segunda reflexão proposta neste ensaio parte da seguinte camada de ressignificação da relação entre o estrangeiro e o local: o processo contemporâneo de glo- 
balização. As bases poéticas eleitas para tal são os diálogos entre José Brites, poeta português imigrante nos Estados Unidos da América, e Paulo Leminski, o escritor um terço curitibano, um terço polaco e o restante japonês.

Leminski quis ser "um grande poeta inglês / do século passado" (2013. p. 31) compreendendo que só mesmo a poesia possibilita o desejo de alguém ser coisa do passado, e virou um kami-quase que dominou a arte do haikai, inspirado sobretudo pela obra do poeta japonês Matsuo Bashô - do qual, aliás, escreveu uma biografia poética. Colocados os ingredientes no liquidificador da materialidade, Leminski se tornou um dos maiores poetas brasileiros do século XX.

Neste poema de Leminski (Figura 1), por exemplo, identifica-se o produto da globalização quase desenfreada. A colagem com efeito semiótico grafa em letras maiúsculas diversas marcas de produtos estrangeiros (sobretudo estadunidenses), enquanto a única marca genuinamente brasileira (casas pernambucanas) é relegada à escrita em letras minúsculas. Trata-se de se estabelecer hierarquia entre o que vem de fora e o que é produzido aqui mesmo. Trata-se, diria José Brites, do amerdicanizamento da vida.

\section{PARKER \\ TEXACO \\ ESSO \\ FORD}

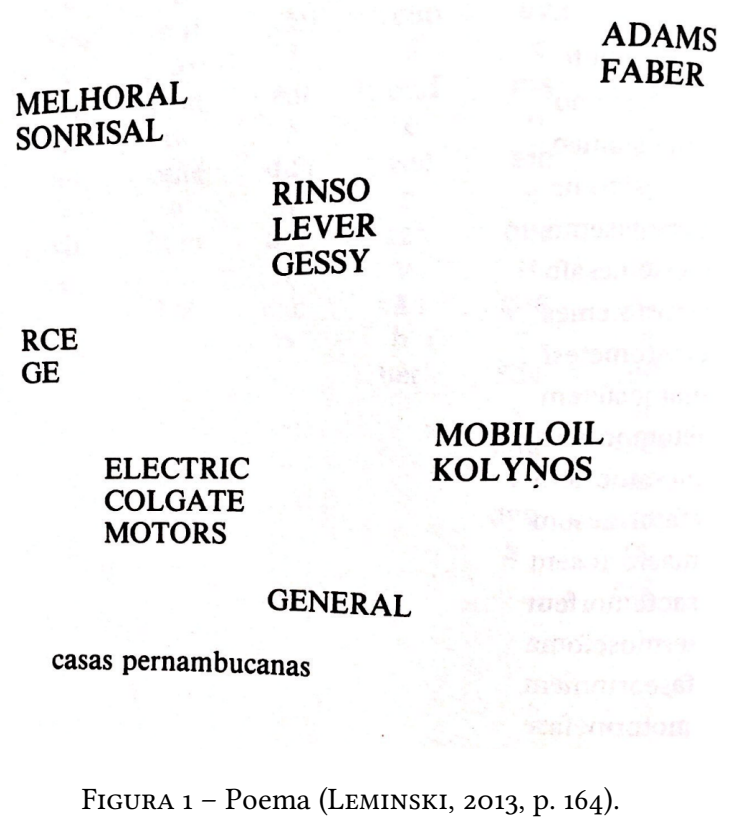

Em Imigramar (1981), Brites denuncia as mazelas enfrentadas pelo imigrante português residente nos Estados Unidos da América. A chamada ambígua de Imigramantes pontua: "Portugal / e/ EstardesUnidos / na América" (BRITES, 1981, p. 
24). Estaria o poeta convocando seus conterrâneos ao ajuntamento ou somente diagnosticando a des-união dos imigrantes por lhes faltar qualquer coisa de nacionalismo fora de Portugal?

Segundo Benedict Anderson (2008), a nação é uma comunidade imaginada, através da qual múltiplos indivíduos se sensibilizam (voluntariamente) a uma pertença coletiva, simplesmente pela consciência de que outras pessoas compartilham (involuntariamente, posto que sua nacionalidade não é escolha delas próprias) da mesma imaginação, levando-as inclusive a sacrificarem suas vidas pelo espectro imaginado.

O historiador estadunidense lembra que o desenvolvimento de um sentimento patriótico só foi possível a partir da inclusão social das classes populares: dos escravos e dos crioulos indígenas nas ex-colônias, por exemplo, onde, em geral, a condição nacional foi mais precoce do que na Europa.

O avanço do processo globalizatório segue uma mesma tendência, mas, ao invés de incorporar as camadas mais baixas à sociedade estabelecida, tenta minguar as fronteiras territoriais, mantendo, todavia, as hierarquias culturais, de modo a convocar inúmeras populações estrangeiras à adesão de um mesmo comportamento global. Boaventura de Sousa Santos afirmou: "Todas as culturas tendem a considerar os seus valores máximos como os mais abrangentes, mas apenas a cultura ocidental tende a formulá-los como universais" (SANTOS, 1997, p. 19).

A solução poética de José Brites para lidar com o aculturamento (tão necessário ao imigrante que persegue sua inserção social quanto ao local que, bombardeado de correspondências anglófonas de fora, sai ao encalço de uma inclusão global) se aproxima do que Bernstein (1997, p. 112) chamou de "histrionização (...) da insinceridade da forma a par da do conteúdo". Através do exagero, temperado com um tom cômico (cujas referências máximas para Bernstein seriam os irmãos Chico e Grouxo Marx), a poesia deve subverter as estruturas da cultura dominante, a partir da ruptura dos nexos linguísticos e comunicativos mais básicos.

Em "O manny das promoções", Brites manipula os idiomas português e inglês de maneira a criar um efeito altamente sarcástico e completamente reflexivo sobre a situação do imigrante português em solo norte-americano. Jogos de palavras como os neologismos speakar e speedando, conjugações tipicamente lusófonas de dois verbos ingleses, ou a aglutinação de palavras do jargão coloquial estadunidense com uma condução poética mormente lusitana, elevam a poesia à extrema histrionizacão sobre a qual falava Bernstein:

O Manny das Promoções

Sandwich aqui

hot dog ali

hamburger acolá 


\begin{abstract}
pizza mais além
o Manel Lambão

(maquinando por semanas

as horas as duas)

virou Manny Speed.
\end{abstract}

Está-lhe à porta

nova promoção.

E a mulher até

já saiu do shop

e televisa-se em casa

no gozo enredado

das novelas diárias.

Ou vai ao store

com o credit card

arejar um pouco

a charging account

uma vez que o Manny

vai speedando dólares.

Rente à noitinha

toda apertada

nas curvas da moda

ela dá ride

até o drive-in

ao bar do motel

ou sítios que sítios.

Mas corre boato

que luso-americana

só toda inveja

de Tónia's situation

anda com ganas

de speakar com o Manny

sobre o young boy

de certa gas station... (BRITES, 1981, p. 42-43)

Leminski também o faz no poema papajoyceatwork. O poorirish e as yesternighteternidades, ou a expressão "Yes, I no" tecem um idioma híbrido e gestante de contradições que buscam descontruir os elos de ligação tão imprescindíveis a uma relação comunicacional. É porque a poesia da contracultura não se propõe comunicativa; antes pelo contrário: explode as convenções e sobrevive somente diante de uma anomia gramatical, ciclicamente a reconfigurando:

$$
\text { papajoyceatwork }
$$


(Noite. Joyce começa a escrever)

Madmanam eye! Light gone out!

(Cai no papel)

Musmakesomething! Reverythming!

(Morde os lábios e gargalha)

A poorirish is a writer mehrlichtsearching, yesternighteternidades!

(Troveja. Relâmpagos iluminam o quarto. Joyce prossegue)

Thomasmorrows? Horriver!

Nice and sweet - the speech of England, damnyou! Dont?

Must destroy it, just like a destroyer would do it yourself! Como um verme.

Yes, I no.

Done to Ireland! What have they done? It will do.

Beforeblacksblanco, we are even, this very evening! Think is so.

My vengeance will be as big as say a country as big as say Brazil.

Someday my prince will come. Our prince: Seabastião!

Arrise, Lewisrockandcarroll!

Waterrestrela, am I a dayer?

Just a wakewriter. (LEMINSKI, 2013, p. 157)

\section{Quão nacional? O norte que é sul}

Depois de Clarice explicar o ser-se estrangeiro no processo de colonização, e Brites e Leminski desenharem a globalização em poesia e semiótica, Frederico Barbosa indica uma terceira camada de reflexão, agora sobre o próprio brasileiro forasteiro dentro do Brasil.

A transição entre a colonização e a globalização se estabelece em um eixo meramente temporal, já que ambos os processos reproduzem comportamentos semelhantes em diferentes momentos da História. Minha proposta, agora, é levar a discussão entre globalização e nacionalismo excludentes a um eixo espacial, de modo que, uma vez que suas fases são temporalmente simultâneas, seus fenômenos acontecem em diferentes níveis territoriais e geográficos.

A sobreposição do espaço geográfico em detrimento dos impactos temporais não exclui, por óbvio, a construção de uma identidade nacional que sempre se estabelece em uma tensão dialética entre a construção do presente através de uma determinação do passado. Como alerta Immanuel Wallerstein, "a dimensão temporal do passado é central e inerente à conceptualização de "povo" (WALLERSTEIN, 1991, p. 78, tradução nossa).

Mas, para Wallerstein, o passado social, diferente do passado real, é manipulável como uma argila macia (1991, p. 78). A construção da identidade nacional, por conseguinte, é um processo variável e inconstante, mas que persegue sempre uma tradição passada que justifique a exclusão daquele que, no presente, desconhece ou conscientemente não se propõe a atualizá-la. Wallerstein indica que 
"o passado é uma ferramenta que as pessoas usam umas contra as outras"2 (1997, p. 78 , tradução nossa).

Os instrumentos de atualização do passado de um grupo social pretendem estreitar e afirmar os laços inconscientemente naturalizados entre seus membros, concedendo-lhes um sentimento de pertença. Mais: delimitam a fronteira entre um e outro espectro cultural, já que, ao sentir-se parte de uma identidade cultural compartilhada pelos seus semelhantes, o indivíduo exclui a possibilidade de participar de outra cultura. Além disso, enumera categorias que o fazem reconhecer quem é ou não seu congênere.

Todavia, ao buscar uma teoria contemporânea que pudesse abrigar as conceptualizações de raça, nação e grupo étnico, através de um recorte de classe, Wallerstein percebe que não é só no eixo temporal que se constrói tais noções. Para tanto, o autor desloca sua análise para o eixo espacial e afirma que "a divisão axial do trabalho dentro do sistema-mundo engendrou uma divisão espacial do trabalho" (WALlerstein, 1977, p. 79, tradução nossa). É esta organização que distancia, por exemplo, as nações do centro e da periferia, do Sul e do Norte, do Ocidente e do Oriente.

No debate que proponho na terceira parte deste ensaio, pretendo analisar como um poeta pernambucano representa sua relação de "estrangeiro" com o sudeste brasileiro, mesmo estando dentro de um mesmo país, fazendo parte de uma mesma construção de identidade nacional, ou seja, compartilhando, ainda que parcialmente, de uma mesma memória coletiva.

A autora Svetlana Boym (2001, p. 135, tradução nossa) afirma que "a identidade cultural (...) envolve jogos quotidianos de esconde-esconde que apenas os nativos jogam, regras de comportamento não escritas, piadas compreendidas em apenas meias palavras, um senso de cumplicidade". Dentro do Brasil, há jogos em que nem sequer os próprios brasileiros conhecem as regras: tente convocar um colega paulistano para jogar adedanha ou um amigo cearense para jogar stop! ${ }^{3}$

Pernambucano, o poeta Frederico Barbosa em Mapas de Viagem (2004) - coleção de poemas inscrita na obra Brasibraseiro (composta com Antônio Risério) relata a experiência do nordestino que chega a São Paulo. Este êxodo, intensificado a partir dos anos 1950, é atualizado em poesia no século XXI. São Paulo é, segundo o autor, um "oxímoro máximo": ao mesmo tempo que é "megavila", é também "provincianópole":

1. mais prazer encontro eu lá

\footnotetext{
2 No original: "Pastness is a tool persons use against each other". Vale ressaltar que o autor utiliza o vocábulo "pastness" para se referir a um sentimento que rememora um determinado passado para, a partir dele, criar bases para o comportamento presente.

3 De fato, a essência e o objetivo dos jogos são os mesmos, mas há regras que variam de uma cidade para outra.
} 
morar em são paulo

é viver em fuga

cidade escapista

essa sem praia

megavila

provincianópole

oxímoro máximo

capital do interior

a alegria começa

como promessa de norte

utópico

quando a estrada atravessa

o trópico

(...)

7 - as cidades e seus donos

há cidades desconfiadas

impessoais misteriosas

recife são paulo

em que se mora por empréstimo

de aluguel de passagem

sem se sentir dono

como inquilino temporário

mas que ninguém tem

há cidades que por mistério

se entregam por inteiro

salvador rio de janeiro

em que cada morador

é proprietário verdadeiro

em que todo o povo

sente-se e afirma-se dono

em todo gesto de menor jeito

(...)

12 - pernambucano paulistano

cada são paulo a que retorno

toca tanto que é ruim

na marginal eu quase choro 


\begin{abstract}
só porque me sinto vir
pernambucano paulistano

como tantos por aqui

tenho-a minha toda e tanto

que não a posso possuir (BARBosA e Risério, 2004, pp. 89; 95; 100).
\end{abstract}

O fluxo migratório dos habitantes do norte e nordeste do Brasil para o sudeste, em especial para os estados do Rio de Janeiro e de São Paulo, no século XX, apresentava uma perspectiva de esperança, já que as megalópoles aparentemente ofereciam mais vagas de emprego e uma oportunidade de vida mais otimista.

Mas Barbosa percebeu que "morar em são paulo / é viver em fuga" (BARBOSA e RisÉRIO, 2004, p. 89). Sair de sua cidade natal para contemplar as luzes da Avenida Paulista não inibe a sensação de eterna alma fugidia.

Há algo de deslocado (desterritorializado) no sentimento de nacionalismo que atravessa nordestinos e sulistas. A partir da alegoria sugerida por Benedict Anderson, de que a ideia de nação seria algo como "um banquete discutido por centenas de pessoas anônimas, que não se conhecem entre si” (2008, p. 58), vale ressaltar que determinadas características identitárias de grupos sociais de regiões específicas de um país muitas vezes barram o efeito aglutinador de uma identidade nacional (o sotaque, a estrutura do corpo, a cor da pele). Ainda que todos saibam que o banquete irá acontecer, alguns têm a certeza de que para ele não serão convidados.

A São Paulo de Frederico Barbosa é uma cidade "em que se mora por empréstimo / de aluguel de passagem / sem se sentir dono / como inquilino temporário / mas que ninguém tem" (BARBosA e RisérIo, 2004, p. 95), é um local de eterna transição, cujo asfalto das avenidas já não pode ser penetrado por novas sementes para quem quiser firmar raízes.

Ao chegar em São Paulo, "a alegria começa / como promessa de norte / utópico" (BARBOSA e Risério, 2004, p. 89). A representação poética nos permite entendê-la como tradução do seguinte: no Brasil, a divisão social do trabalho elevou o eixo Rio-São Paulo à categoria de centro e, simultaneamente, transformou os demais territórios em periferia.

São Paulo, latitudinalmente ao sul de Pernambuco, se apresenta como o norte (tão) promissor (quanto u-tópico) para Barbosa. U-tópico (cuja origem etimológica remonta ao "não lugar") porque, ao mesmo tempo em que o migrante pretende se estabelecer peremptoriamente, a cidade o leva a uma atmosfera de eterna transitoriedade. É a utopia como o ideal, mas também como o ilocável.

Frederico Barbosa expressa, em seus "mapas de viagem", o sentimento da desterritorialização que Deleuze e Guattari diagnosticaram em Kafka, mas conjuga 
ainda as outras duas características da literatura menor: em seus poemas, tudo é também político e adquire um valor coletivo.

Sentir-se estrangeiro em seu próprio território é a revelação da poesia do pernambucano. Isto porque, nas metáforas líricas, o norte e o sul não têm direção prédeterminada.

\section{(In)Conclusão (A)poética}

Ser estrangeiro tem uma dimensão na linguagem que não necessariamente coaduna com o senso comum. O conto de Clarice Lispector ensina que há vezes em que mesmo o habitante mais antigo de um território pode ser tratado como estranho àquele ambiente, o que acontece nos processos de colonização.

Tentei demonstrar que desterritorializar, conceito caro a Deleuze e Guattari quando da análise da literatura de Kafka, representa um incômodo desejo de fuga. Aquele que se sente estrangeiro em seu próprio território (ou em sua própria espécie) foge à convenção colonial ao buscar afirmar uma identidade própria.

A condição do estrangeiro resulta de uma modelagem cultural: designa-se quem é o de fora ao estabelecer-se as regras do jogo. Na contemporaneidade, a globalização é o processo que visa a uma normatização universal. Neste sentido, os poemas de Paulo Leminski e José Brites foram resgatados para ilustrar a potência histriônica que a poesia tem ao troçar das regras impostas pelos impérios globais. Neles, a língua inglesa é uma mera matéria-prima maleável.

Há ainda o sentir-se estrangeiro diante daqueles que (teoricamente) compartilham uma mesma identidade nacional consigo. Frederico Barbosa conta o sentimento do nordestino que chega em São Paulo e suas inquietações diante daquela megavila provincianópole. Tudo ali é um convite à fuga, mas para onde? Além disso, há uma identidade paulistana? O que Barbosa nos permite reconhecer é que, no Brasil, o sentido do "norte utópico" (ao mesmo tempo ideal e ilocável) é para o sul geográfico.

Portanto.

\section{Referências}

Anderson, Benedict. Comunidades imaginadas: reflexões sobre a origem e a difusão do nacionalismo. São Paulo: Companhia das Letras, 2008.

Barbosa, Frederico; Risério, Antonio. Brasibraseiro. São Paulo: Landy Editora, 2004 .

Bernstein, Charles. A-poética. Revista Crítica de Ciências Sociais, Coimbra, v. 47, p. 101-122, 1997.

Bosı, Alfredo. Dialética da colonização. São Paulo: Companhia das Letras, 1992. 
Boym, Svetlana. The future of nostalgia. New York: Basic Books, 2001.

Brites, José. Imigramar. NewArc: PAB Publications, 1981.

Deleuze, Giles; Guattari, Félix. Kafka: por uma literatura menor. Rio de Janeiro: Imago Editora, 1977.

Leminski, Paulo. Toda poesia. São Paulo: Companhia das Letras, 2013.

LisPector, Clarice. Todos os contos. [e-book]. Rio de Janeiro: Editora Rocco, 2016.

Pepetela. A geração da utopia. Alfragide, LeYa, 1992.

Philip, Marlene Nourbese. Discourse on the logic of language. In: PhILIP, Marlene Nourbese. She tries her tongue, her silence softly breaks. Charlottetown: Ragweed Press, 1989. p. 56-59.

Ribeiro, Darcy. O povo brasileiro. São Paulo: Companhia das Letras, 2006.

Santos, Boaventura de Sousa. Descobrimentos e encobrimentos. Revista Crítica de Ciências Sociais, Coimbra, v. 38, p. 5-10, 1993.

Santos, Boaventura de Sousa. Por uma concepção multicultural de direitos humanos. Coimbra: Revista Crítica de Ciências Sociais, Coimbra, v. 48, p. 11-32, 1997.

Telmo, Antonio. Arte poética. Lisboa: Guimarães Editores, 1993.

WALlERSTEIN, Immanuel. The construction of peoplehood: racism, nationalism, ethnicity. In: BALIBAR, Etiene; WALLERSTEIn, Immanuel. Race, nation, class: ambiguous identities. Nova Iorque: Verso, 1991.

Recebido em 18 de novembro de 2019.

Aprovado em $1^{\circ}$ de março de 2020 .

\section{Resumo/Abstract/Resumen}

\section{Ser-se estrangeiro: forjas (a)poéticas de desterritorialização}

\section{Lucas Augusto da Silva}

A partir de um quadro teórico que conjuga o conceito de desterritorialização tal qual desenvolvido por Gilles Deleuze e Félix Guattari, e da teoria a-poética de Charles Bernstein, analisa-se três movimentos de fuga à territorialidade, permeados pelos processos de colonização moderna e globalização contemporânea, debruçando-se sobre três bases literárias. Primeiro intenciona-se analisar como este processo ocorre na relegação da condição de estrangeiro aos nativos de um território na exploração colonial com enfoque no conto "A legião estrangeira" de Clarice Lispector; depois, investiga-se o movimento de globalização pela consolidação da língua inglesa como padrão comunicacional pela análise crítica de poemas de Paulo Leminski e José Brites; finalmente, a partir de uma leitura dos 
poemas que compõem "Mapas de Viagem" de Frederico Barbosa, conclui-se sobre os hiatos da composição de uma identidade nacional gerados pelas desigualdades e mazelas internas deflagradas no caso brasileiro.

Palavras-chave: desterritorialização, a-poética, estrangeiro, nacionalismo.

\section{Being Foreign: (A)poetic Forges of Deterritorialisation}

\section{Lucas Augusto da Silva}

Based on a theoretical framework that combines the concept of deterritorialisation developed by Gilles Deleuze and Félix Guattari, and the A-poetics theory of Charles Bernstein, this paper analyses three movements of escape from territoriality, permeated by the processes of modern colonization and contemporary globalization, addressing three nuclear literary bases. First, we intend to analyse how colonial exploration relegates the status of the natives of a territory to 'foreigner', through an analysis of the story "The Foreign Legion" by Clarice Lispector. Secondly, the globalization movement is investigated through the consolidation of English as a communication template and through the critical analysis of poems by Paulo Leminski and José Brites. Finally, from a reading of the poems that make up "Travel Maps" by Frederico Barbosa, we draw conclusions on the gaps in the composition of a national identity generated by inequalities and abundant internal ills, in the case of Brazil.

Keywords: deterritorialization, a-poetics, foreigner, nationalism.

\section{Ser extranjero: forjas (a)poéticas de desterritorialización}

\section{Lucas Augusto da Silva}

Sobre la base de un marco teórico que combina el concepto de desterritorialización desarrollado por Gilles Deleuze y Félix Guattari, con la teoría a-poética de Charles Bernstein, se analizan tres movimientos de escape de la territorialidad, impregnados por los procesos de colonización moderna y globalización contemporánea, abordando tres bases literarias: en primer lugar, se analiza cómo ocurre este proceso en la relegación del estatus de estranjero en los nativos de un territorio por causa de la explotación colonial, mediante un estudio del cuento "La Legión Extranjera" de Clarice Lispector; en segundo lugar, se investiga el movimiento de globalización a través de la consolidación del inglés como estandar comunicacional, mediante el análisis crítico de poemas de Paulo Leminski y José Brites; y, en último lugar, a partir de una lectura de los poemas que componen "Mapas de Viajes" de Frederico Barbosa, se concluye sobre los hiatos en la composición de una identidad nacional generados por las desigualdades y los males internos, abundantes en el caso brasileño.

Palabras clave: desterritorialización, a-poética, extranjero, nacionalismo. 